\title{
A Blended Learning Strategy for Professional English Course in a Cloud Learning Environment
}

\author{
Qiusha Min and Guanghui Wu
}

\begin{abstract}
Recently English plays an increasingly important role in science. A lot of educational institutions in non-native English-speaking countries offer professional English courses for academic purposes. However, students involved in these courses exhibit low learning motivation and hence lead to disappointing learning results. This paper presents a blended learning strategy for effective teaching and learning of professional English. This strategy integrates a cloud learning environment (CLE) to provide blended learning activities, blended learning resources, and blended learning assessments. During the learning process, students have more opportunities to participant in learning activities and access to learning resources. The combination of summative and formative assessments reduces students learning anxiety and increases their motivation to learn. The experimental results show that the student performance in professional English is significantly improved by this blended learning strategy and more than 90 percent of students satisfy with this course. Thus, this study confirms the positive effect of blended learning on professional English course.
\end{abstract}

Index Terms-Blended learning, professional English, instructional strategy, cloud learning environment.

\section{INTRODUCTION}

In recent years there is a trend that English plays an important role in the field of science. A study of publications from all over the world covered in the Science Citation Index Expanded (Web of Science) finds that $96 \%$ of all scientific publications in the Science Citation Index Expanded published in the year 2000 were written in English, and an increasing number of journals are being written in English during the past few decades [1]. Consequently, it is necessary to teach and learning professional English for academic purposes, especially for non-native English-speaking students.

However, professional English teaching in Chinese universities is confronted with a number of difficulties, e.g. the low interest students, a lack of eligible teaching staffs and suitable teaching strategies [2]. In this paper, we attempt to propose a blended learning strategy, which integrates a cloud learning environment (CLE), to increase student satisfaction towards professional English teaching and improve the

Manuscript received August 4, 2016; revised August 30, 2016. This work was financially supported by Specific funding for education science research by self-determined research funds of CCNU from the colleges' basic research and operation of MOE (No. CCNU16JYKX09).

The authors are with the school of educational information technology, Central China Normal University, No.152 Luoyu Road, Wuhan,Hubei, China (e-mail: qiusham@ mail.ccnu.edu.cn, 2452460134@qq.com). effectiveness of professional English learning.

\section{RELATED WORK}

Blended learning generally refers to a strategy that combines e-learning with traditional face-to-face instruction so as to provide the most efficient and effective instruction experience. Researchers have proved that this learning strategy is effective for many subjects, e.g. Nursing [3], Software Engineering [4], and Semiconductor Device [5]. Language learning can also benefit from it [6], [7]. Combining with e-learning environment, the students have the opportunity to set and organize their own pace of study and individual learning for English. Additionally, blended learning can increase student learning motivation and hence improve learning performance [8].

One of the most important components in blended learning is an online learning environment which provides abundant learning resources and various learning activities for students. Recently, with the development of cloud computing, CLE can be used to apply blended learning. One of the most significant advantages of CLE over traditional IT systems is that the data are not restricted to a specific institution and can be accessed anytime and anywhere from any digital device [9]. Applications and data would be stored remotely on cloud servers. There is no need for concerns about the data storage space and access. Many studies have shown that the integration of CLE into the student learning process can effectively improve their academic competence, such as reflection abilities [10], and critical thinking skills [11].

Based on a review of previous literature, this paper proposes the idea of utilization of a blended learning strategy which integrates a CLE to improve the effectiveness of professional English course and increase student's satisfaction towards this course.

\section{BLENDED LEARNING STRATEGY}

A blended learning strategy which integrates CLE into a professional English course is presented in this section. The overview of this strategy is described in Fig. 1. There are three main components in the strategy, which are blended learning activities, blended learning resources, and blended learning assessments.

\section{A. Blended Learning Activities}

Learning activities are very important for students to master the learning objective. They can provide students with the necessary skills, knowledge, and experience. For traditional professional English course, the learning activities 
are restricted in the classroom by face-to-face interaction. However, in the CLE, some in-class sessions can be replaced with online learning activities. A CLE used in this study is shown in Fig. 2.

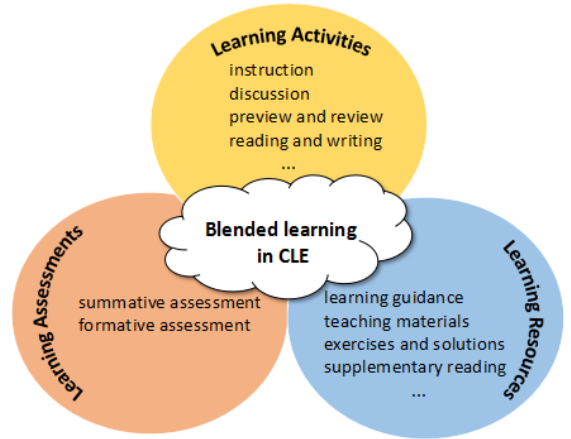

Fig. 1. Overview of blended learning strategy for professional English course.

The main learning activities in a professional English course include instruction, discussion, lecture-note review, reading, writing and so on. When the lecture organizes these activities, he/she should consider student learning preferences and alignment of course goals and objectives with face-to-face and online activities. For example, discussion can be implemented in the classroom by a traditional way. However, students may be reluctant to participant in this discussion since the topic is difficult and they may be afraid of embarrassing themselves in front of the classmates. In this case, it is preferable to organize an online discussion and hence students have time to explore the topic by themselves, leading to a deeper understanding. Therefore, the professional English course based on blended learning strategy provides two types of learning activities, i.e. classroom activity and online activity. A proper combination of these activities can maximize learning effectiveness for professional English.

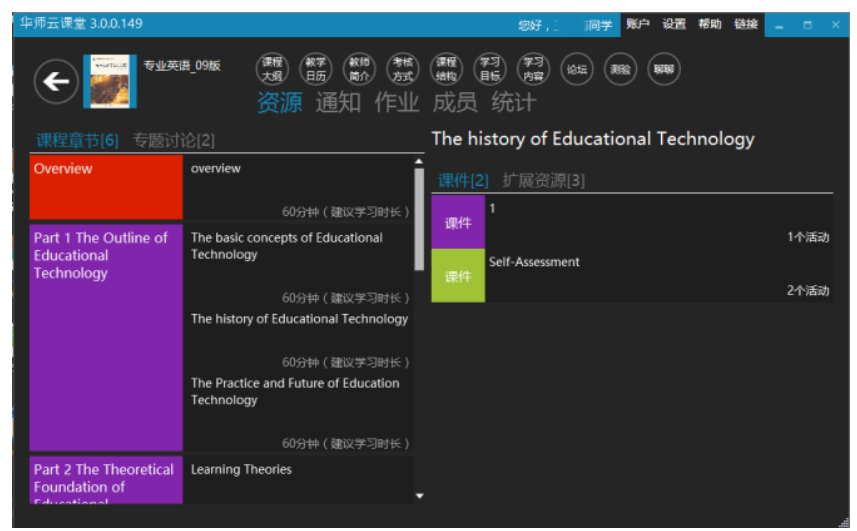

Fig. 2. Screenshot of the leaning activities interface in the CLE.

\section{B. Blended Learning Resources}

Learning resources provide important opportunities for students to explore ideas and knowledge, collaborate, and solve problems. The successful implementation of learning activities requires the use of a variety of resources that support the student to conduct a task. These resources may include books, manipulatives, videos, and online materials. The lecture can upload these learning resources into CLE and then students are able to view these materials at any time in any place. Therefore, knowledge and skills can be obtained outside classroom and students can implement independent learning in online environment. Fig. 3 shows the example learning resources provided by the CLE.
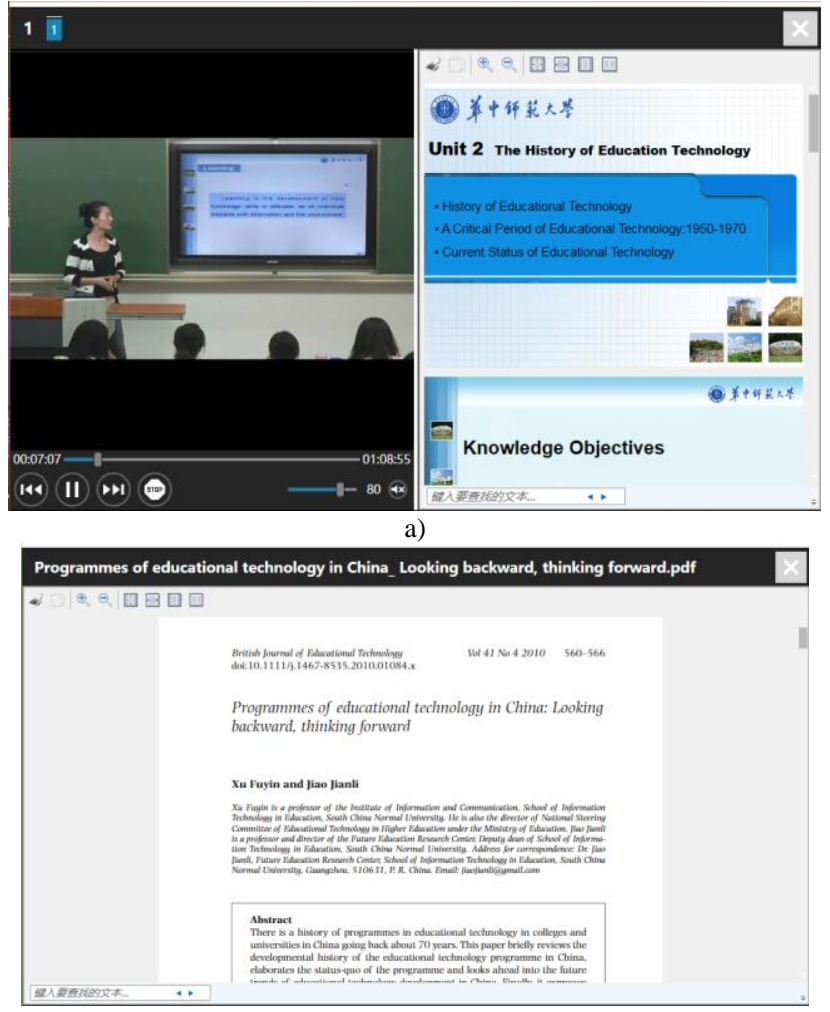

b)

Fig. 3. Screenshot of the leaning resources interface in the CLE. a) lecture video and b) supplementary reading.

\section{Blended Learning Assessments}

Learning assessment techniques are normally divided into two categories: summative and formative. The goal of summative assessment is to evaluate student learning at the end of a semester. Final exams are an example of summative assessment. Formative assessment techniques are used to monitor student learning during the learning process. For traditional professional English course, student performance is usually assessed by a summative method since it is very hard to record student learning process. In the CLE, student's online activities can be monitored and their learning information, e.g. learning paths, questions, and assignments, can be stored in a student profile (see Fig. 4). Therefore, it is possible for lectures to combine summative assessment with formative assessment in order to give an appropriate evaluation of student learning gains.

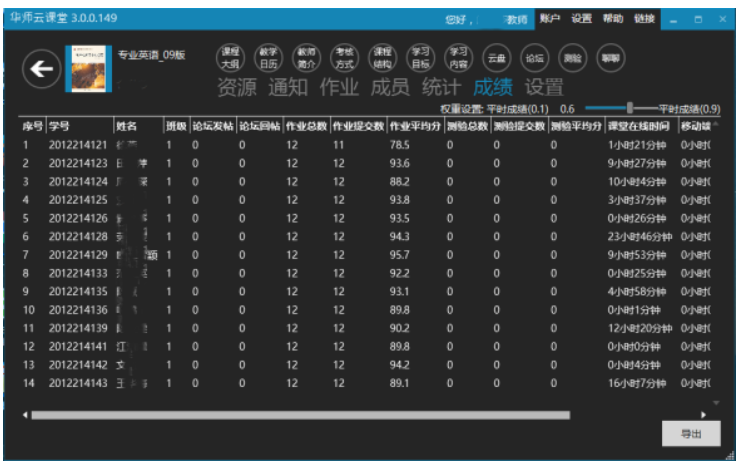

Fig. 4. Screenshot of an interface of the leaning process for each student in the CLE. 


\section{EXPERIMENT AND RESULTS}

An experiment to determine the effectiveness of this blended learning strategy was conducted in our university. The data were collected from a course entitled "Professional English for Educational Technology" which was taught to Chinese students in the 1 st semester of the 2014/2015 academic year.

\section{A. Procedure}

A total of 14 students ( 3 males and 11 females) with an average age of 19 years participated in this course. A one-group pretest-posttest design was adopted to evaluate the effectiveness of this blended learning strategy for the professional English course. The experiment procedure is shown in Fig. 5 which includes four stages, i.e. pre-test, instruction and learning, post-test, and post-questionnaire and interview of learning attitude.

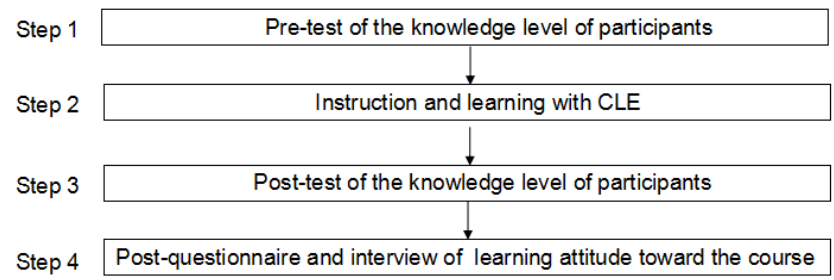

Fig. 5. Experimental process.

\section{B. Results}

After finishing each phase of the study, the students' data were collected. The data of pre-test and post-test are used to evaluate student learning improvements by the blended learning strategy. The details of the exam results for both preand post-test are shown in Table I. Comparing the exam scores of two tests, the t-test obtained $t=9.50, p<0.001$, so a significant difference $(\mathrm{p}<0.05)$ was found between pre- and post- tests. It is clear that the average test score of post-test (84.14) was substantially higher than that of pre-test (58.21). Consequently, these results indicate that the student performance in professional English is significantly improved by this blended learning strategy which is in line with theoretical expectations.

TABLE I: EXAM SCORES FOR PRE-TEST AND POST-TEST

\begin{tabular}{|l|l|l|l|c|}
\hline & Size & Mean & $\begin{array}{l}\text { Standard } \\
\text { deviation }\end{array}$ & T-test \\
\hline Pre-test & 14 & 58.21 & 9.46 & \multirow{2}{*}{9.50} \\
\hline Post-test & 14 & 84.14 & 4.04 & \\
\hline
\end{tabular}

TABLE II: STUDENT OVERALl SATISFACTION LEVEL WITH THIS COURSE

\begin{tabular}{|l|c|c|}
\hline Scale & Frequency & Percent \\
\hline Unsatisfied & 1 & 7.2 \\
\hline Somewhat satisfied & 3 & 21.4 \\
\hline Satisfied & 8 & 57.1 \\
\hline Very satisfied & 2 & 14.3 \\
\hline Can't answer & - & - \\
\hline Total & 14 & 100 \\
\hline
\end{tabular}

The investigation of students' satisfaction with the "Professional English for Educational Technology" course was conducted by a questionnaire. The overall satisfaction scale with this blended learning course for professional English is shown in Table II. Students presented a high degree of satisfaction with this course, with $14.3 \%$ being very satisfied, $57.1 \%$ being satisfied and $21.4 \%$ being somewhat satisfied.

We also interviewed some of students participated in the course in order to obtain their personal opinions towards the blended learning strategy. A student indicated that "This course is useful for the field of educational technology and I hope to learn more about professional English". Some students reported that they felt less anxious due to the change of the evaluation method that combines summative with formative assessment for their learning performance. Using this evaluation method, students could know their learning performance and obtain immediate feedback during the learning process. This treatment makes students feel more in control and safe in their learning environments. The experimental results confirmed that the blended learning strategy has a positive impact on students' learning attitudes towards professional English course.

\section{CONCLUSION}

The purposes of this study were to present a blended learning strategy for professional English course in a CLE, and to conduct an evaluation of the effectiveness of this strategy. The experimental results have demonstrated that the blended learning strategy can significantly improve student learning performance and promote their satisfaction with professional English course. Since this strategy integrates a CLE, it can provide abundant learning resources, various learning activities, and personal learning record and hence give students the opportunity to learn independently and deeply. The results of this paper can be useful to educational institutions which offer professional English course for non-native English-speaking students.

\section{REFERENCES}

[1] M. Bordons and I. Gómez, "Towards a single language in science? A Spanish view," Serials, vol. 17, pp. 189-195, 2004

[2] G. Li, D. Chen, and M. Zhu, "Notice of retraction current situation and countermeasures for enhancing professional English teaching in the Chinese universities," in Proc. 2010 International Conference on Optics, Photonics and Energy Engineering (OPEE), Wuhan, pp 415-417, 2010.

[3] R. Rossiter and J. Day, "Cycles of reflection and challenge: Using sequential blended learning strategies to enhance student understanding of, and transition to, the nurse practitioner role in Australia," Collegian, vol. 23, pp. 159-166, June 2016.

[4] W. Yongxing, "Blended learning design for software engineering course design," in Proc. International Conference on Computer Science and Software Engineering, Wuhan, pp. 345-348, 2008.

[5] H. Hussin, M. Muhamad, and J. Karim, "Design and implementation of blended learning model in semiconductor device course," in Proc. 2015 IEEE 7th International Conference on Engineering Education (ICEED), Kanazawa, pp. 176-180, 2015.

[6] I. H. Mirici, I. H. Erten, H. Oz, and S. Tosun, "The proceedings of the 1st globelt conference on teaching and learning English as an additional language, the effects of blended learning on EFL students' vocabulary enhancement," Procedia - Social and Behavioral Sciences, vol. 199, pp. 641-647, August 2015

[7] X. Wang, Y. Yang, and X. Wen, "Study on blended learning approach for English teaching," in Proc. IEEE International Conference on Systems, Man and Cybernetics, San Antonio, TX, pp. 4641-4644, 2009.

[8] M. A. S. Mustapa, M. Ibrahim, and A. Yusoff, "Engaging vocational college students through blended learning: Improving class attendance and participation," Procedia - Social and Behavioral Sciences, vol. 204, pp. 127-135, August 2015. 
[9] L. Chao, "Cloud computing for teaching and learning: Strategies for design and implementation," Hershey, PA: Information Science Reference, 2012.

[10] Y.-T. Lin, M.-L.Wen, M. Jou, and D.-W. Wu, "A cloud-based learning environment for developing student reflection abilities," Computers in Human Behavior, vol. 32, pp. 244-252, March 2014

[11] P. Thaiposri and P. Wannapiroon, "Enhancing students' critical thinking skills through teaching and learning by inquiry-based learning activities using social network and cloud computing," Procedia Social and Behavioral Sciences, vol. 174, pp. 2137-2144, February 2015.

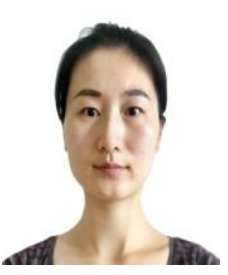

Qiusha Min received the B.S degree in educational technology from Jianghan University, Wuhan, China, in 2007, and the Ph.D. degree in engineering from Dublin City University, Dublin, Ireland, in 2013.

She is currently a lecturer in the School of Educational Information Technology, Central China Normal University. Her main research interests include web/mobile application development, multimedia systems, and educational technologies, focusing on blended learning approaches.

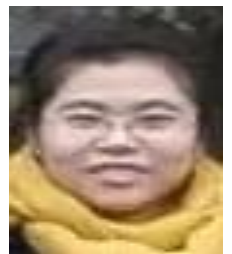

Guanghui Wu received the B.S degree in art from Wuhan Donghu University, Wuhan, China, in 2014.

She is currently a postgraduate in the School of Educational Information Technology, Central China Normal University. Her main areas of research are science communication, and educational technologies. 